\title{
Acute Myeloid Leukemia with Recurrent Genetic Abnormalities
}

National Cancer Institute

\section{Source}

National Cancer Institute. Acute Myeloid Leukemia with Recurrent Genetic Abnormalities. NCl Thesaurus. Code C7175.

A group of acute myeloid leukemias characterized by recurrent genetic abnormalities,

mainly balanced translocations. (WHO, 2001) 